\title{
Raciocínio Lógico e Computação: Descobrindo Estratégias de ensino por meio da Olimpíada Brasileira de Informática
}

\author{
Erika Raquel Silva dos Santos, Fábio Cristiano de Souza Oliveira, Ivaldo Barbosa da \\ Mota Neto ${ }^{1}$.
}

${ }^{1}$ Instituto Federal de Educação, Ciência e Tecnologia do Sertão Pernambucano - Campus Petrolina (IF-SERTÃO PE).

\begin{abstract}
This paper describes the experience of an extension project, which aims to stimulate interest in computing and for science in general, through specific teaching strategies with ICT aid, encouraging the participation of students, elementary school in marathons local and national programming as the Olympiad of Informatics involving the resolution of computational problems.
\end{abstract}

Resumo. Este trabalho relata a experiência de um projeto de extensão, cujo objetivo é estimular o interesse pela Computação e pela Ciência em geral, através de estratégias de ensino especificas com o auxílio de TIC's, favorecendo a participação dos estudantes, do ensino fundamental, em maratonas de programação locais e nacionais como a Olimpíada Brasileira de Informática que envolve a resolução de problemas computacionais.

\section{Introdução}

A expansão das empresas de infraestrutura e tecnologia no país, e a adoção acelerada de serviços de Tecnologias da Informação e Comunicação (TIC) pelas iniciativas públicas e privada e ainda pela própria sociedade, tem provocado um déficit de mão de obra especializada no país. De acordo com o IDC (EXAME, 2013), em 2015, o Brasil terá 117 mil vagas abertas para profissionais de tecnologia sem que os empregadores encontrem pessoal qualificado para atendê-las.

Entre as especialidades mais requisitadas, está a de desenvolvimento de software, que faz o uso das linguagens de programação. As linguagens de programação são, normalmente, ensinadas nos cursos técnicos de informática e nos cursos de graduação relacionados à computação. Por outro lado, o baixo ingresso de estudantes em áreas relacionadas às TICs aliado o alto índice de evasão dos cursos de graduação tem agravado a situação (WALTRICK, 2013).

Com o propósito de atrair mais jovens para este campo da ciência, a Sociedade Brasileira de Computação (SBC) realiza anualmente a Olimpíada Brasileira de Informática (OBI). A OBI está dividida em três modalidades: universitária, programação e iniciação, sendo esta última, destinada aos alunos do ensino fundamental. A modalidade iniciação é subdividida em duas categorias nível 1 para crianças até o sétimo ano, e nível 2 para alunos até o nono ano. A proposta da modalidade é despertar o gosto por problemas de computação e detectar talentos potenciais para programação (OBI, 2015).

Nessa linha, surgiu o Projeto Programadores do Futuro uma iniciativa que conta com o apoio do Conselho Nacional de Desenvolvimento Científico (CNPq) e tem entre outros 
objetivos, o de favorecer a participação de crianças do sexto e sétimo ano do ensino fundamental na modalidade iniciação nívell da OBI. A proposta do projeto também visa desenvolver e ensinar habilidades como a sistematização do pensamento e a concentração. Para Nickerson (1982), o ensino de lógica e programação de computadores funciona como um veículo para o desenvolvimento dessas habilidades.

Este artigo relata a experiência de um projeto de extensão que oferta treinamento em raciocínio lógico através de um curso de Formação Inicial e Continuada (FIC) para crianças de 09 a 11 anos regularmente matriculadas no ensino básico. Dessa forma, este trabalho apresenta as estratégias de ensino empregadas para atrair a atenção, minimizando a evasão e despertando o interesse pela computação enquanto ciência.

O artigo está estruturado da seguinte forma: a seção 1 apresentou o contexto do trabalho. A seção 2, apresenta alguns trabalhos relacionados com a proposta deste artigo. Na sequência, a seção 3 descreve de forma detalhada as abordagens empregadas no treinamento de lógica. Por último, a seção 4 apresenta as conclusões e os resultados obtidos até o momento.

\section{Trabalhos Relacionados}

Muitos trabalhos têm sido feitos na tentativa de atrair alunos para aprender programação de forma lúdica. Vargas et al. (2014) desenvolveu um trabalho falando sobre a importância de ambientes divertidos e interativos no ensino e aprendizagem de programação, como: $K o d u^{1}$ da Microsoft e o Scratch ${ }^{2}$ desenvolvido pelo Massachusetts Institute Technology(MIT).

Geraldes et al. (2014) fala em seu trabalho, sobre as reflexões positivas e negativas no ensino de programação para crianças, trazendo argumentos de especialistas e educadores de como isso pode influenciar no desenvolvimento da criança.

Outra experiência relevante para a proposta deste trabalho é apresentada por Barros et al. (2009). Neste artigo é relatada a preparação de alunos para a Olimpíada Brasileira de Informática (OBI), visando à participação dos estudantes na modalidade iniciação. Os autores destacam os benefícios para os estudantes que participam de competições, pois ao se engajar em uma Olimpíada, o aluno pode criar novos vínculos com a escola e também mudar sua atitude com relação às disciplinas temas das competições.

A importância do estudo da lógica para o processo de aprendizagem é reconhecida (SCOLARI, 2007), e visa auxiliar estudantes a raciocinar, compreender conceitos básicos e prepará-los melhor para o entendimento de tópicos mais avançados. Barros et al. (2009), ainda ressalta que além de todos esses resultados positivos, as Olimpíadas têm também criado oportunidades para desenvolvimento pessoal, ocasionando impacto social positivo na vida de vários alunos carentes.

\section{O Projeto}

Para Surlo et al. (2010), os projetos de extensão são parte integrante das atividades de investigação e de ensino, além disso criam um espaço de intercâmbio acadêmico, principalmente, quando envolvem pessoas com diferentes realidades. Os autores destacam a necessidade e a importância da criação de ações cotidianas com o intuito de transformar as atividades de extensão em parte integrante das atividades de investigação e de ensino. Dessa

${ }^{1}$ Disponível em: <http://www.kodugamelab.com/>. Acesso em: 20/05/2015.

${ }^{2}$ Disponível em: $<$ https://scratch.mit.edu/scratch2download/ $>$ 
forma, é possível perceber também, que a extensão aproxima a população da universidade, bem como de um ambiente com recursos diferenciados.

Nesta perspectiva, o projeto de extensão aqui descrito teve como objetivo capacitar estudantes regularmente matriculados no sistema de Educação Básica, especificamente, nos sextos e sétimos anos do ensino fundamental. As turmas são divididas em níveis: Nível Iniciação $\left(6^{\circ} \mathrm{e}\right.$ $7^{\circ}$ ano do ensino fundamental), Nível Programação: o Júnior $\left(8^{\circ}\right.$ e $9^{\circ}$ ano) e o Nível $1\left(1^{\circ}\right.$ e $2^{\circ}$ ano do ensino médio). Tanto o Nível Programação Júnior e o Nível Programação Nível 1 possuem duas turmas em horários opostos: um pela manhã e outro pela tarde, com dois encontros por semana. Já a turma de Iniciação possui um único encontro aos sábados com três horas de duração. Para esta última turma não se faz necessário o ensino de programação, pois a OBI exige apenas raciocínio lógico e matemático.

\section{Planejamento e Cronograma}

Com o propósito de atrair a atenção dos alunos foram planejadas aulas que iniciassem do mais simples e do mais lúdico até chegar ao ponto primordial do curso: resoluções das questões da OBI. Sendo assim, montou-se estratégias de ensino que buscassem o melhor ensino/aprendizagem.

O curso foi formatado com sessenta horas (60h) de duração. O planejamento realizado considerou um cronograma de execução dividido em três fases: a primeira com jogos e brincadeiras de maneira a trabalhar a sistematização do pensamento; a segunda com resolução aplicação de questões de lógicas através de competições e trabalhos em grupos; e a última abordou a resolução de questões de provas de anos anteriores da OBI.

\subsection{Primeira Fase}

A primeira fase foi projetada para iniciar o curso com uma base lúdica, evitando impactos indesejados nos discentes e teve duração de quinze horas (15h).

Nos encontros iniciais foram utilizadas dinâmicas para que os alunos exercitassem o raciocínio entre essas podemos citar a dinâmica em grupo da Alfândega ${ }^{3}$.Além das dinâmicas foi utilizada a ferramenta de jogo disponibilizada pela Code.org ${ }^{4}$. A escolha foi feita por possuir um ambiente colorido e harmônico, e cheio de personagens conhecidos como os passarinhos do "Angry Birds" e os zumbis e plantas do jogo "Plants vs Zombies", este jogo foi o que mais chamou a atenção dos estudantes.

De acordo com Vargas (2014) o Code.org surgiu de iniciativas dos gigantes do mundo tecnológico, como o fundador da Microsoft, Bill Gates, e o fundador da rede social Facebook, Mark Zuckeberg, visando estimular o ensino de programação no ensino fundamental. O autor enfatiza que projetos como o Code.org influenciam no aprendizado de maneira positiva, um ambiente lúdico retirando a ideia de que linguagens de programação não podem ser aprendidas por crianças.

Antes de iniciar o jogo, cada aluno com o auxílio do professor criou um cadastro no site colocando um código no final, pois assim o professor tem acesso ao processo de cada aluno cadastrado com o seu código, como também é possível perceber se o aluno resolveu o nível da maneira mais simples ou de uma maneira mais longa ou até mesmo se o aluno não conseguiu

\footnotetext{
${ }^{3}$ Disponível em:<http://goo.gl/eDixmW>. Acesso em: 10 de mar. De 2015.

${ }^{4}$ Disponível em: <http://code.org/>.Acesso em: 10 mar. De 2015.
} 
resolver determinado nível. Assuntos como estruturas de condição e repetição são abordados de forma lúdica. Outro jogo online utilizado foi "Travessia das Cabras" onde a classe foi dividida em duplas, na qual as duas duplas que cumprissem o desafio primeiro seriam sagradas vencedoras.

\subsection{Segunda Fase}

A segunda fase teve duração de nove horas, e estimulou os alunos a resolverem questões de lógica. Um exemplo foi a Gincana de Lógica, onde a sala foi dividida em cinco grupos, cada um com um nome de uma cor para diferenciá-los. Foram entregues a cada grupo quatro questões de lógica para serem resolvidas dentro de uma hora. Cada questão inicialmente valia 100 pontos, contudo toda vez que o grupo trazia uma resolução errada perdia 10 pontos na respectiva questão. No final do tempo foi calculado os pontos obtidos por cada grupo, no qual os integrantes do grupo vencedor receberam chocolates. Foi percebido o entusiasmo e um bom envolvimento dos estudantes.

\subsection{Terceira Fase}

A terceira fase consistiu da exposição sobre a forma como as questões da OBI são apresentadas. Esta fase também foi caracterizada pela resolução de questões da OBI e, principalmente, pelo o envolvimento através de mini gincanas.

\section{Conclusões}

Com as estratégias de ensino, tentou-se de forma lúdica e prazerosa o ensino de lógica computacional para crianças do ensino fundamental. Foram utilizadas de modo que a diversão e a competitividade envolvesse cada vez mais os estudantes.

Nota-se, nesta mesma turma que a falta de encontros intercalados durante a semana em alguma medida dificultou o desempenho dos alunos nas aulas já que as mesmas só ocorriam durante os sábados, e no restante da semana os discentes não tentavam resolver as questões pedidas pelo professor, desta forma não praticando em casa aquilo que era passado em sala, impossibilitando um maior aprendizado.

Durante as resoluções das questões, foi observado um déficit na maioria dos estudantes nas áreas de língua portuguesa e matemática, prejudicando drasticamente o aprendizado já que a interpretação de texto auxilia na compreensão do que deve ser feito. Já a matemática afetava na própria resolução da questão em si.

Por mais que as dificuldades possam ter sido um obstáculo para um maior desenvolvimento do projeto e do aprendizado, deve-se perceber que é a primeira vez que é implantado um curso preparatório para a OBI na região, trabalhando com crianças e adolescentes do ensino fundamental e médio. Outro detalhe também, é que os discentes nunca tiveram contato com algoritmos computacionais, então era essencial um ensino lúdico.

Com a realização deste projeto foi possível contribuir para a inclusão digital de crianças num universo com muitas possibilidades. Foi possível despertar o interesse pela computação e assim mostrá-la como uma ciência em expansão. Além disso, foi possível apresentar os cursos relacionados a área disponíveis na instituição.

\footnotetext{
${ }^{5}$ Disponível em: 〈 http://goo.gl/9wH2hQ>. Acesso em: 14 de mai. De 2015.
} 
CBIE-LACLO 2015

Anais do XXI Workshop de Informática na Escola (WIE 2015)

\section{Referências}

BARROS, L.; RIBEIRO, Suellen Patrícia S.; OEIRAS, J. Projeto de Extensão Universitária para apoio e realização da Olimpíada Brasileira de Informática em Escolas. In: XXIX Congresso da SBC-XVII WEI, Bento Gonçalves. 2009.

DINÂMICAS DE GRUPO ONLINE. Alfândega. Disponível em <http://goo.gl/o6i9g6>. Acesso em: 13 mai 2015.

EXAME. Falta de profissionais de TI se agravará no Brasil, diz IDC. São Paulo: Abril, 2013.Disponível em: <http://goo.gl/f3XwTg>. Acesso em: 10 abr. 2015.

GERALDES,W.B. Programar é bom para as crianças? Uma visão crítica sobre o ensino de programação nas escolas. Texto Livre, Linguagem e Tecnologia. Instituto Federal de Goiás. V. $7 \mathrm{~N}^{\mathrm{o}}$ 2, 2014.NICKERSON, R. S. Computer programming as a vehicle for teaching thinking skills. Thinking: The Journal of Philosophy for Children, v. 4, n. 3/4, p. 4248, 1982.

JOGOS EDUCATIVOS ONLINE. A travessia das cabras. Disponível em < http://goo.gl/ymTyMB > . Acesso em: 14 mai. 2015.

MEDEIROS,T.J. ;SILVA,T.R. ; ARANHA,E.H.S. Ensino de programação utilizando jogos digitais: uma revisão sistemática da literatura. CINTED-UFRGS,V. $11 \mathrm{~N}^{\circ} 3$, dezembro, 2013.

Scolari, A. T.; Bernardi, G.; Cordenonsi, A. Z. (2007) "O Desenvolvimento do Raciocínio Lógico através de Objetos de Aprendizagem”, In: RENOTE - Revista Novas Tecnologias na Educação, Porto Alegre: UFRGS, Centro Interdisciplinar de Novas Tecnologias na Educação. Dezembro. Vol. 5 No 2. ISSN 1679-1916.

SURLO,G.P.;DIAS,M.T.F. Mediação e cidadania nos núcleos de prática jurídica: a experiência da universidade federal de ouro preto. Anais do XIX Encontro Nacional do CONPEDI, Fortaleza - CE. Junho,2010.

VARGAS,R.M. Ambientes de programação voltada para crianças sob a perspectiva da engenharia semiótica. In: Programa de pós-graduação strictu sensu em Sistemas de Informação e Gestão do Conhecimento,2015, Belo Horizonte.

VIEL,F.;RAABE,A.;ZEFERINO,C.Introdução à Programação e à Implementação de Processadores por Estudantes do Ensino Médio. In:CONGRESSO BRASILEIRO DE INFORMÁTICA NA EDUCAÇÃO, 3,2014.

WALTRICK, Rafael. Alta taxa de desistência na universidade causa déficit de engenheiros.Londrina: Gazeta do Povo, 2013. Disponível em: <http://goo.gl/yp9Qmg>. Acesso em: 10 mai. 2015. 